\section{The Chemical Exploration of the Stratosphere}

For his Friday evening discourse at the Royal Institution on November 6, Prof. F. A. Paneth took as his subject "The Chemical Exploration of the Stratosphere". Prof. Paneth pointed out that while the temperature and the electrical state of the stratosphere have been the object of many investigations, its chemical composition has seldom been studied. If winds are absent, or at least rare in the stratosphere, we should expect a partial separation of the atmospheric gases under the gravitational field of the earth. In order to decide this question of the stillness of the stratosphere, samples of air have to be collected. For this purpose, the sending up of automatic devices in unmanned balloons is the most efficient method. In collaboration with the Meteorological Office of the Air Ministry, Prof. Paneth and Dr. E. Glückauf, working at the Imperial College of Science and Technology, have developed methods for the automatic collection and subsequent analysis of air samples from the stratosphere. From the first results, published a year ago, it was concluded that up to $18 \mathrm{~km}$. no definite change in the chemical composition of the stratosphere occurred, but that at a height of $21 \mathrm{~km}$. the relative amount of the light gas helium has already distinctly increased. During the last few months, this has been confirmed by further successful flights reaching more than $23 \mathrm{~km}$.

SImILAR investigations have lately been started by Prof. E. Regener, in Stuttgart, using larger balloons; in one of his samples, from a height of more than $28 \mathrm{~km}$., he found an oxygen deficit, in good agreement with the helium surplus detected in the London flights. The only two air samples obtained by manned stratosphere balloons confirm these findings : Prokofiev's sample collected over Russia in 1933 at a height of $19 \mathrm{~km}$. showed no variation in its composition; but the air brought back by Capt. Stevens and Capt. Anderson from $22 \mathrm{~km}$. over the United States already revealed a slight oxygen deficit. All this supports the conclusion that from about $20 \mathrm{~km}$. onwards the stratosphere is quiet enough to permit a partial separation of its constituents by gravity. Neither the London nor the Stuttgart samples show a gradual change in the composition of the atmosphere in proportion to altitude. This is of special interest as it proves that in spite of their relative quietude, the air masses even of higher layers of the stratosphere are liable to disturbances, probably corresponding to weather conditions.

\section{The Royal Society of Arts}

For his inaugural address delivered on November 4 to the Royal Society of Arts, Sir Henry McMahon, chairman of the Society, took as his subject "One Hundred and Eighty Years of Pioneer Work by the Royal Society of Arts". The Society was founded in 1754 "for the Encouragement of Arts, Manufactures and Commerce" at a time when there were no departments of Government, societies or institutions to deal with such matters as Colonies, agriculture, forestry, fine arts, health, trade or industry.
In the early days, the field of work was divided into six sections, each being left to the charge of a separate committee. Money prizes, or premiums as they were called, and in some cases gold and silver medals, were then offered for specific objects, and in this way a very great stimulus was provided for improvements in all directions. The agricultural industry in particular derived much benefit from such a policy. At the time of the foundation of the Society, agricultural methods were largely based on medieval practice. In the second half of the eighteenth century, the Society took an important share in developing a more scientific outlook. The prizes offered by the Committee on agriculture covered a very wide range, including the improvement in the quality and yield of established crops, such as wheat, barley, oats and rye, the introduction of new grasses and roots for cattle feeding, better methods of cultivation, the invention of new types of agricultural machinery and the improvement of existing models, the use of manures, soil analysis, the management of sheep and eattle, and indeed almost every aspect of what is now understood by the term 'scientific agriculture'.

ThE offer of rewards did not always produce results. For example, a handsome reward was offered and renewed for no less than forty-six years (1774-1820) for an effective corn-reaping machine, without success. One of the most useful pieces of work for which the Society can claim credit was the introduction of the swede and mangel-wurzel into Great Britain. Remarkable results were also achieved by the Society in connexion with afforestation carried out in the period 1758-1835, anticipating in fact the work of the present Forestry Commission, which was not founded until 1919. Much attention has also been paid by the Society to the polite arts, the importance of encouraging the art of drawing in many employ. ments, trades and manufactures being recognized from the start. The introduction of industrial exhibitions was a feature of the pioneer work in this direction, and the success of the Exhibition of British Art in Industry in 1935 was an indication of the desire on the part of both designers and manufacturers of the present time to increase this spirit of co-operation.

\section{Prevention of War}

THERE can be no doubt of the general and passion. ate determination of the great majority of the thinking youth of the world to prevent another world war. This desire is strongly expressed by the New History Society, of 132 East 65th Street, New York, and illustrated by its offer of prizes amounting in the whole to five thousand dollars for the best papers submitted on the subject of "How Can the People of the World achieve Universal Disarmament?" The essays are to be of not more than two thousand words in length, and the prizes are variously graded from one thousand dollars downwards, so that there seems abundant opportunity for any helpful contribution sent in from any part of the world to receive some recognition. We recommend all 